\title{
Utilização de concentrados sanguíneos em tratamentos de cavidade cirúrgica após remoção de cisto periapical - Relato de caso
}

\author{
Use of blood concentrates in surgical cavity treatments after periapical cyst removal - Case report \\ Uso de concentrados en sangre en tratamientos de cavidad quirúrgica posteriores a la extracción
}

periapical del quiste - Reporte de caso

Recebido: 05/05/2021 | Revisado: 12/05/2021 | Aceito: 13/05/2021 | Publicado: 30/05/2021

\author{
Nadiery Mainara Brito \\ ORCID: https://orcid.org/0000-0002-2253-7584 \\ Faculdade Patos de Minas, Brasil \\ E-mail: nadymainarabrito@gmail.com \\ Eduarda Vinhal Parrião \\ ORCID: https://orcid.org/0000-0003-2174-0043 \\ Faculdade Patos de Minas, Brasil \\ E-mail dudinhavinha121@gmail.com \\ Marcelo Dias Moreira de Assis Costa \\ ORCID: https://orcid.org/0000-0001-9148-3674 \\ Universidade Federal de Uberlândia, Brasil \\ E-mail: marcelodmac@yahoo.com.br \\ Lia Dietrich \\ ORCID: https://orcid.org/0000-0001-7887-8591 \\ Clínica Privada, Brasil \\ E-mail: dietrichlia.ld@gmail.com \\ Victor da Mota Martins \\ ORCID: https://orcid.org/0000-0001-6631-6161 \\ Faculdade Patos de Minas, Brasil \\ E-mail: victortag@hotmail.com
}

\begin{abstract}
Resumo
Cistos são cavidades patológicas recobertas por tecido epitelial. Os cistos periapicais são as lesões císticas mais comuns dos maxilares e originam-se de um granuloma, através de um processo inflamatório crônico, que estimula a proliferação de remanescentes epiteliais na região do periápice. São assintomáticos e considerados achados radiográficos. O tratamento dos cistos periapicais varia de acordo com a extensão da lesão. Objetivo: Descrever um caso clínico da remoção de um cisto periapical combinada à apicectomia, retrobturação e preenchimento da cavidade cística com concentrado sanguíneo. Relato de caso: Paciente E.L.G, sexo masculino, 43 anos, procurou a clínica odontológica com queixa principal de "dentes quebrando". Durante anamnese e exame clínico foi notado um aumento volumétrico de consistência mole no fundo do rebordo vestibular anterior da maxila, sintomático ao toque, na região dos incisivos direitos. Foi solicitada uma radiografia panorâmica e pôde-se observar uma lesão radiolúcida de limites definidos; com margem de esclerose óssea, de aproximadamente um centímetro e meio em seu maior diâmetro, unilocular, arredondada, envolvendo o ápice radicular do dente 12 e estendendo-se para a região do dente 11. O exame anatomopatológico confirmou o diagnóstico de cisto periapical. Foi realizada curetagem cística seguida de apicectomia e retrobturação com MTA. Para promoção do reparo ósseo, optou-se pelo preenchimento da cavidade cística com biomaterial A-PRF+. Considerações: O A-PRF+ apresentou-se como uma alternativa de relevante importância no controle do quadro inflamatório, auxiliando no processo de reparo dos tecidos moles e duros.
\end{abstract}

Palavras-chave: Cistos odontogênicos; PRF; Cisto periapical; Regeneração óssea.

\begin{abstract}
Cysts are pathological cavities covered by epithelial tissue. Periapical cysts are the most common cystic lesions of the jaws and originate from a granuloma, through a chronic inflammatory process, which stimulates the proliferation of epithelial remnants in the peri-apex region. They are asymptomatic and are considered radiographic findings. The treatment of periapical cysts varies according to the extent of the lesion. Objective: To describe a clinical case of removal of a periapical cyst combined with apicectomy, retrofilling and filling the cystic cavity with blood concentrate. Case report: Patient E.L.G, male, 43 years old, went to the dental clinic with the main complaint of "teeth breaking". During anamnesis and clinical examination, a volumetric increase in soft consistency was noted at the bottom of the anterior buccal ridge of the maxilla, symptomatic to the touch, in the region of the right incisors. Panoramic radiography was requested and a radiolucent lesion of defined limits was observed; with a bone sclerosis margin, approximately one and a half centimeters in its largest diameter, unilocular, rounded, involving the root apex
\end{abstract}


of tooth 12 and extending to the region of tooth 11. The anatomopathological examination confirmed the diagnosis of periapical cyst. Cystic curettage was performed followed by apicectomy and retrofilling with MTA. To promote bone repair, it was decided to fill the cystic cavity with biomaterial A-PRF +. Considerations: A-PRF + was presented as an alternative of relevant importance in the control of the inflammatory condition, assisting in the soft and hard tissue repair process.

Keywords: Odontogenic cysts; PRF; Periapical cyst; Bone regeneration.

\section{Resumen}

Los quistes son cavidades patológicas cubiertas por tejido epitelial. Los quistes periapicales son las lesiones quísticas más frecuentes de los maxilares y se originan a partir de un granuloma, a través de un proceso inflamatorio crónico, que estimula la proliferación de remanentes epiteliales en la región peri-ápice. Son asintomáticos y se consideran hallazgos radiográficos. El tratamiento de los quistes periapicales varía según la extensión de la lesión. Objetivo: Describir un caso clínico de extirpación de un quiste periapical combinado con apicectomía, relleno y llenado de cavidad quística con concentrado de sangre. Caso clínico: Paciente E.L.G, varón, 43 años, acudió a la consulta odontológica con el principal síntoma de "rotura de dientes". Durante la anamnesis y el examen clínico, se observó un aumento volumétrico de la consistencia blanda en la parte inferior del reborde bucal anterior del maxilar, sintomático al tacto, en la región de los incisivos derechos. Se solicitó radiografía panorámica y se observó una lesión radiolúcida de límites definidos; con margen de esclerosis ósea de aproximadamente un centímetro y medio en su diámetro mayor, unilocular, redondeado, que involucra el ápice radicular del diente 12 y se extiende hasta la región del diente 11. El examen anatomopatológico confirmó el diagnóstico de quiste periapical. Se realizó legrado quístico seguido de apicectomía y relleno con MTA. Para favorecer la reparación ósea, se decidió rellenar la cavidad quística con biomaterial A-PRF +. Consideraciones: A-PRF + se presentó como una alternativa de relevante importancia en el control de la condición inflamatoria, asistiendo en el proceso de reparación de tejidos blandos y duros.

Palabras clave: Quistes odontogênicos; PRF; Quiste periapical; Regeneración óssea.

\section{Introdução}

Os cistos periapicais, também conhecidos como cistos radiculares, são definidos como sendo uma cavidade patológica revestida por epitélio, de origem odontogênica, que contém em seu interior fluido ou restos celulares (Dantas, Dultra, Borges, Dultra, \& Neri, 2014). Tais lesões representam o último passo da progressão dos eventos secundários à estimulação inflamatória do epitélio que reveste o ápice de um dente não vital. Os restos epiteliais de Malassez são comumente a fonte epitelial, oriundos da desorganização apoptótica da bainha de Hertwing (Martins-Filho, et al., 2009; Vasconcelos, Queiroz, Alves Júnior, Germano, \& Vasconcelos, 2012).

Os cistos periapicais constituem cerca de metade a dois terços de todos os cistos odontogênicos e aproximadamente $60 \%$ de todos os cistos mandibulares. Radiograficamente apresentam imagens radiotransparentes, comumente circular ou ovoide, com margens radiopacas afiladas contíguas com a lâmina dura do elemento dentário envolvido. Embora a maioria dos cistos periapicais meçam em média menos de $1,5 \mathrm{~cm}$, variações de diâmetro são encontradas, desde $5 \mathrm{~mm}$ até vários centímetros (Vasconcelos, et al., 2012).

Dentre as terapêuticas possíveis, a enucleação traduz-se na remoção total da lesão cística, sem ruptura. A remoção da peça por inteiro anula a possibilidade de recidiva, exigindo então que a técnica seja executada com bastante cuidado. $\mathrm{O}$ fato de permitir o exame histopatológico integral da lesão é considerado sua principal vantagem. A possibilidade de que seja feita uma biópsia excisional inicial e proporcione o tratamento adequado da lesão também é considerada uma vantagem importante desse método (Freitas, Rosa, \& Sousa, 2000; Neto, Danesi, \& Unfer, 2004; Petterson, 2000; Tommasi, 2002).

Para um prognóstico promissor do tratamento, a ocupação da loja óssea com biomateriais se faz necessário; dentre eles estão às Fibrinas Ricas em Plaquetas (PRF). O PRF é um concentrado de plaquetas sobre uma membrana de fibrina com um excelente potencial de reparação de feridas. Esta membrana é adquirida a partir de sangue autólogo, sem acréscimo de fatores externos. A utilização do gel está fundamentada num conceito de uma terapêutica por liberação de fatores de crescimento. Com o potencial de fornecer proteínas e incutir a síntese de colágeno por parte dos fibroblastos, o gel pode aligeirar a cicatrização de feridas e o processo de reparo dos tecidos (Costa, de Resende, Assis, \& de Barros, 2018).

Com isso, o objetivo deste trabalho é descrever um caso clínico da remoção de um cisto periapical combinada à 
apicectomia, retrobturação e preenchimento da cavidade cística com concentrado sanguíneo e por fim avaliar relevância clínica do uso de PRF na reconstrução óssea.

\section{Metodologia}

Este estudo apresentou caráter qualitativo e descritivo (Estrela 2018), realizado por meio de um relato de caso clínico de um paciente da Policlínica da Faculdade Patos de Minas no município de Patos de Minas- MG.

Foram utilizadas as bases de dados Scielo, Google Acadêmico e PubMed usando como palavras-chave "cistos odontogênicos", "PRF", "retrobturação", "regeneração óssea".

Após o Termo de Consentimento Livre e Esclarecido (TCLE) assinado, o trabalho foi submetido ao Conselho de Ética e Pesquisa em Seres Humanos da Faculdade Patos de Minas (CEP-FPM) e aprovado sob o número de parecer: 4.614.307, seguindo as normas da resolução 466/2012.

\section{Relato de Caso}

Paciente sexo masculino, 43 anos de idade foi encaminhado para clínica odontológica da Faculdade Patos de Minas com queixa principal: "dentes quebrando" (sic). Na anamnese, relatou não fazer uso de medicações de uso contínuo e afirma não ser portador de nenhuma doença de base ou alergias. Relata também ter negligência com sua saúde bucal. Durante anamnese e exame clínico foi notado um aumento volumétrico de consistência mole no fundo do rebordo vestibular anterior da maxila, em região de incisivos direitos (Figura 1).

Notou-se ausência do incisivo central direito. Essa lesão era sintomática apenas ao toque. Diante do quadro clínico foi solicitada radiografia panorâmica para elucidação diagnóstica.

$\mathrm{Na}$ imagem radiográfica pode-se observar uma lesão radiolúcida de limites definidos, com margem de esclerose óssea, de aproximadamente um centímetro e meio em seu maior diâmetro, unilocular, arredondada envolvendo o ápice radicular do dente 12 e estendendo-se para a região do dente 11 . O dente 12 apresentava um pino metálico de grande extensão com tratamento endodôntico insatisfatório.

Diante do aspecto clínico e radiográfico a hipótese diagnóstica foi de cisto periapical originário do dente 12.

Para melhor planejamento cirúrgico solicitou-se uma Tomografia Computadorizada de Feixe Cônico (TCFC). Nas imagens tomográficas observou-se imagem radiolúcida na região de dente 11, estendendo-se até o ápice do dente 12 de aproximadamente um centímetro e meio em sua maior extensão, com grande perda da cortical vestibular e pequena perda da cortical palatina.

Com base nos exames clínicos e radiográficos a hipótese diagnóstica de cisto periapical foi dada e o tratamento de escolha foi curetagem cística, seguida de apicectomia e retrobturação com MTA devido a grande extensão do pino intraradicular e a possibilidade de fratura do mesmo em caso de remoção. Com o intuito de promover a melhora do reparo ósseo, optou-se pelo preenchimento da cavidade cística com biomaterial A-PRF+, auxiliando assim a neoformação óssea e na reação inflamatória pós-operatória.

O procedimento cirúrgico foi realizado mantendo a cadeia asséptica, utilizando clorexidina a $2 \%$ e $0,12 \%$ para antissepsia extra e intraoral, respectivamente. Foram realizadas infiltrações anestésicas na região dos nervos infraorbitários bilateralmente (figura 2), com solução anestésica contendo lidocaína a 2\% com epinefrina 1: 100.000 aproximadamente $4 \mathrm{ml}$ de solução foi utilizada para bloqueio. Anestesias infiltrativas para fins hemostáticos e um bloqueio nasopalatino como complemento foram realizadas. Para acesso a lesão, realizou-se um retalho trapezoidal, com dois alívios e uma sulcular estendendo-se dos elementos 13 a 22 (Figuras 3 e 4). Promoveu-se o descolamento total do retalho e devido ao epitélio do cisto estar preso à mucosa, houve um rompimento do mesmo, evidenciando um líquido amarelo citrino e em meio a este, cristais de 
colesterol (Figura 5). Após a exposição da cavidade cística e com o auxílio da cureta de Lucas, a membrana cística foi devidamente curetada da loja cirúrgica (Figura 6 e 7).

Após completa remoção da cápsula cística, a loja óssea foi irrigada abundantemente com solução fisiológica e suas bordas ósseas foram regularizadas (Figura 8).

Devido ao fato de o paciente dispor de uma ponte fixa com um pino muito longo e haver grande possibilidade de fratura com a sua remoção, optou-se por realizar uma retrobturação e não um retratamento endodôntico e fazendo uso de uma broca, foi realizada uma apicectomia com um corte perpendicular ao longo eixo do dente 12 (Figura 9), removendo-se três milímetros de ápice (delta apical), visando à diminuição de chance de recidiva (Figura 10). A cavidade para retrobturação teve seu preparo feito com broca, retirando parte de gutta percha para posterior inserção de MTA (Figura 11). Após espatulação do material de escolha em placa de vidro estéril, condensou-se o material na cavidade, removendo-se os excessos com uma cureta periodontal (Figura 12).

Assim como planejado, as membranas de A- PRF+ feitas previamente ao procedimento cirúrgico foram inseridas na loja óssea. Para obtenção do A- PRF+ promoveu-se a punção venosa prévia ao procedimento cirúrgico, na veia anticubital com auxílio de escalpe $21 \mathrm{G}$ e tubo coletor a vácuo de $09 \mathrm{~mL}$. Foram coletados seis tubos de $09 \mathrm{ml}$ de sangue durante 4 minutos, os quais foram levados à centrífuga por 8 minutos a uma força de 200G. Após a centrifugação ocorre à separação entre as célu las vermelhas e brancas, obtendo-se A-PRF+ que foi retirado do tubo coletor e armazenado na caixa para prensagem e drenagem, obtendo-se assim as membranas e plugs de A- PRF+ (Figura 13). A cavidade foi preenchida com três membranas/plugs e posteriormente foram posicionadas mais duas pelo lado externo da lesão, visando promoção de melhor resposta tecidual (Figuras 14 e 15).

Por fim, reposicionou-se o retalho e foram realizados pontos simples utilizando fio de nylon $4.0 \mathrm{em}$ toda borda para mantê-lo em posição (Figura 16). 
Research, Society and Development, v. 10, n. 6, e31010615806, 2021

(CC BY 4.0) | ISSN 2525-3409 | DOI: http://dx.doi.org/10.33448/rsd-v10i6.15806

Figura 1 - Aspecto intraoral inicial.

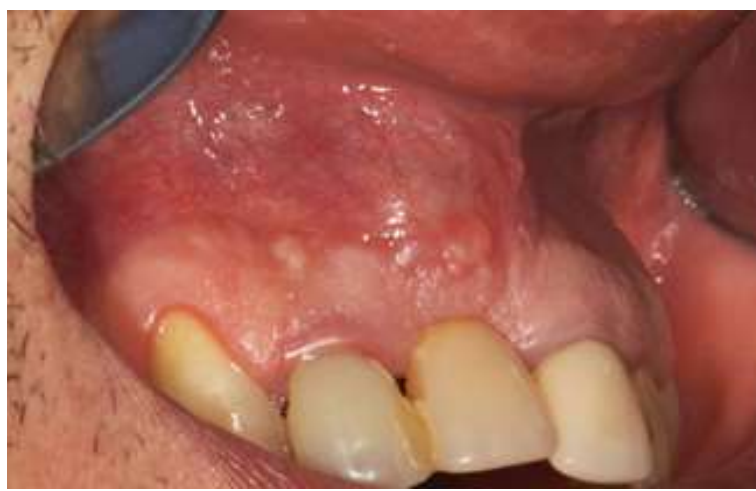

Figura 3 - Momento prévio a incisão.

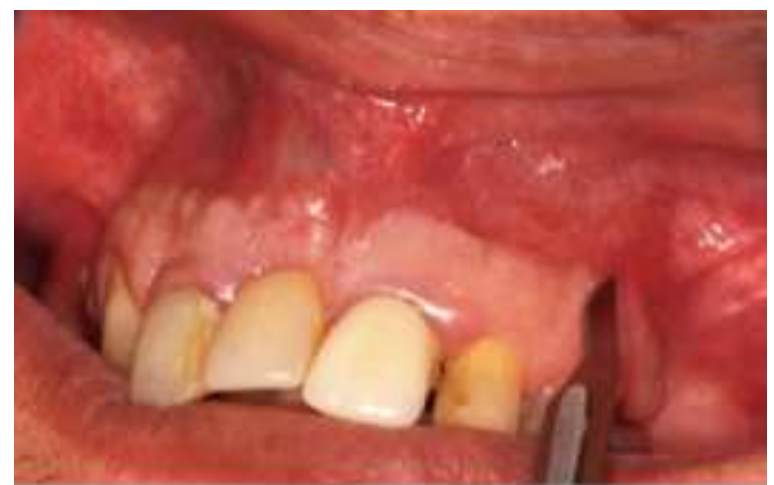

Figura 5 - Descolamento total do retalho e rompimento do cisto evidenciando cristais de colesterol

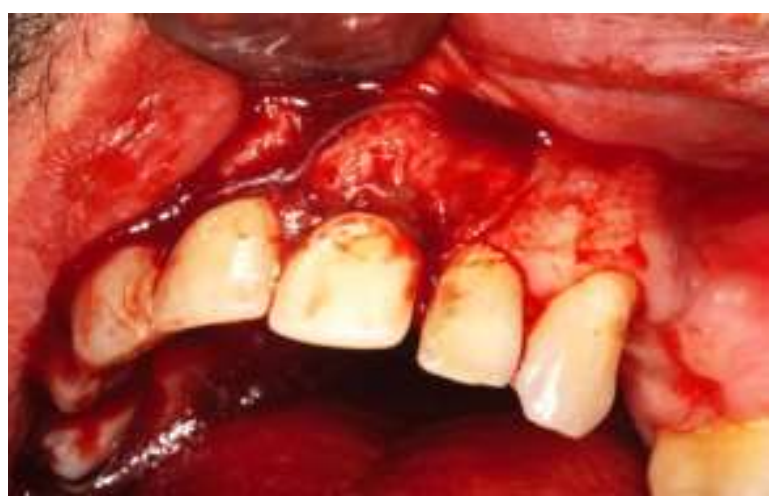

Figura 7 - Curetagem cística.

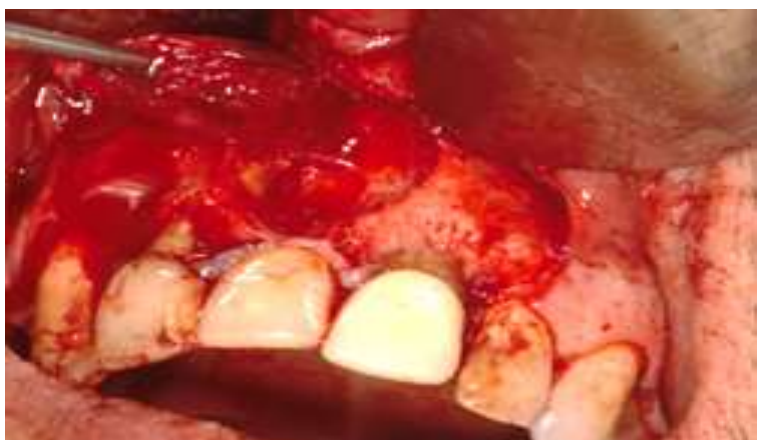

Figura 2 - Infiltrações anestésicas.

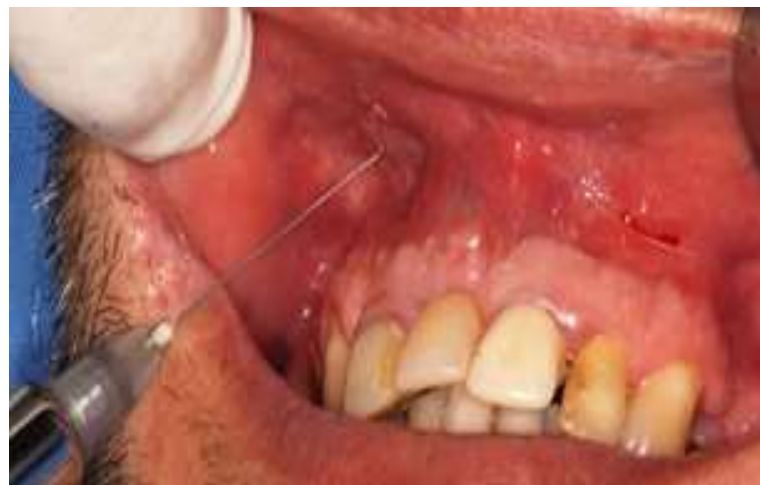

Figura 4 - Retalho trapezoidal.

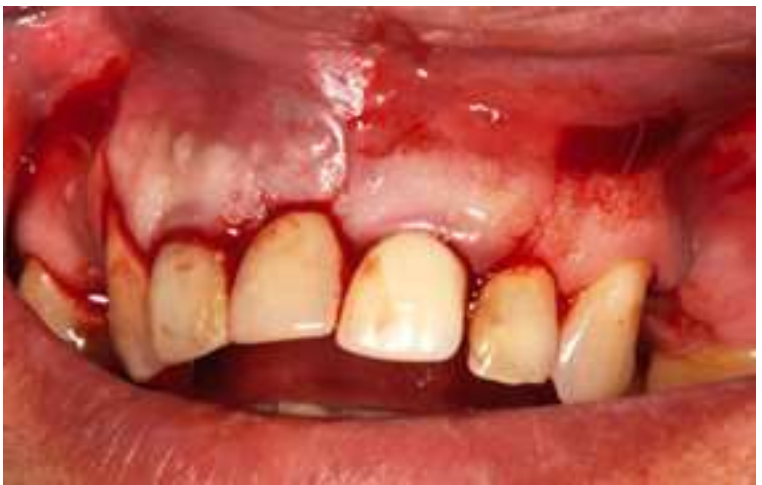

Figura 6 - Curetagem cística.

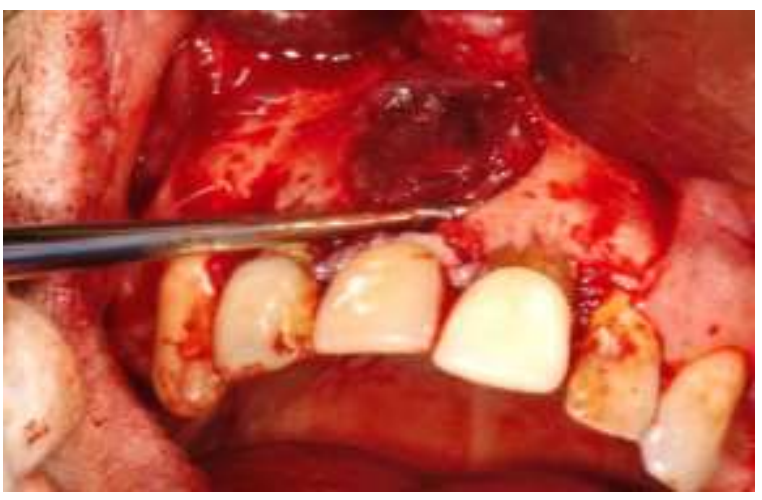

Figura 8 - Loja óssea.

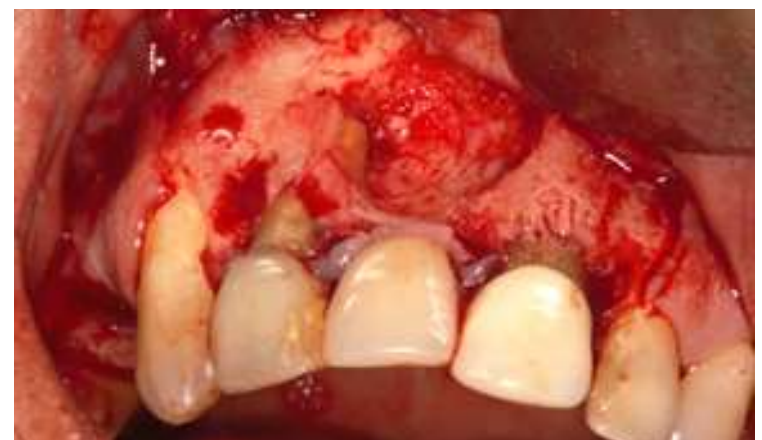


Figura 9 - Broca posicionada para realização de

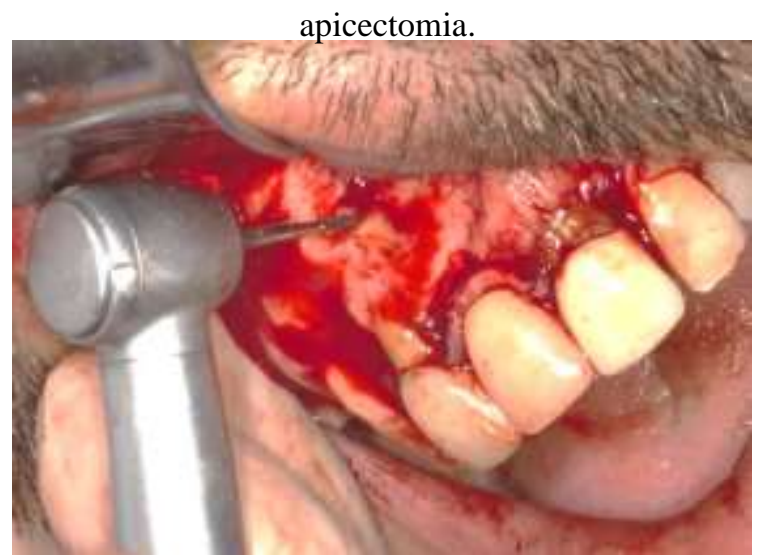

Figura 10 - Remoção do delta apical.

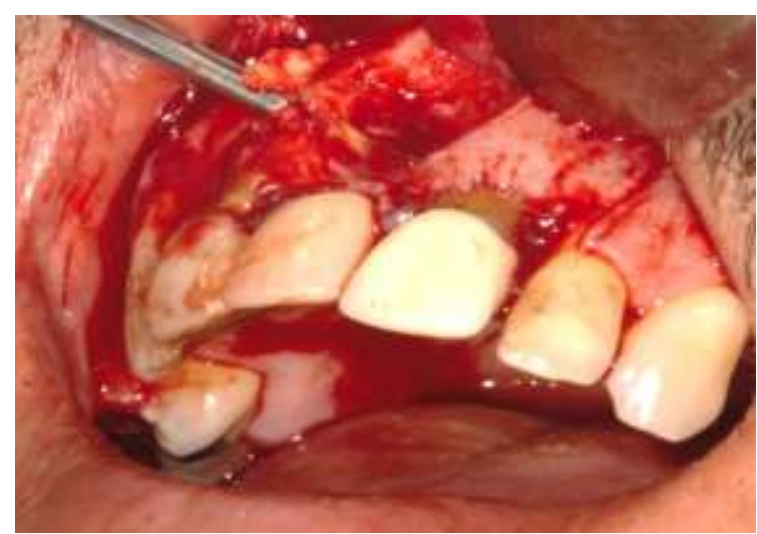

Figura 11 - Cavidade para retrobturação

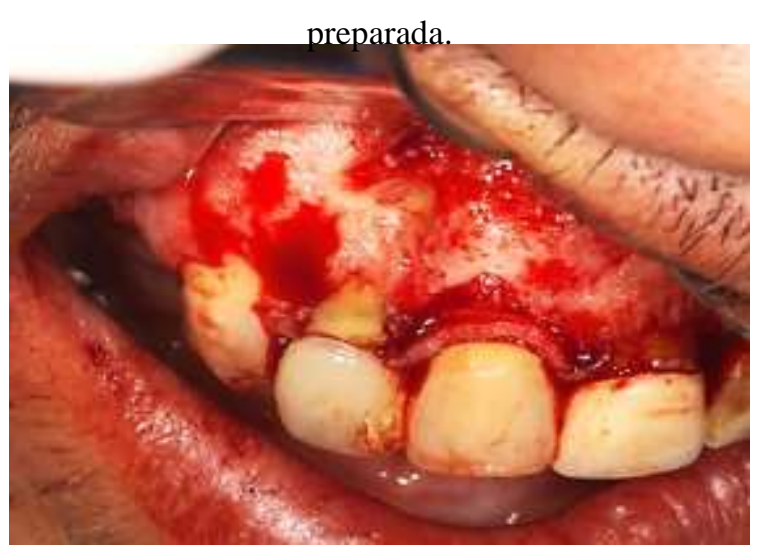

Figura 12 - MTA inserido na cavidade.

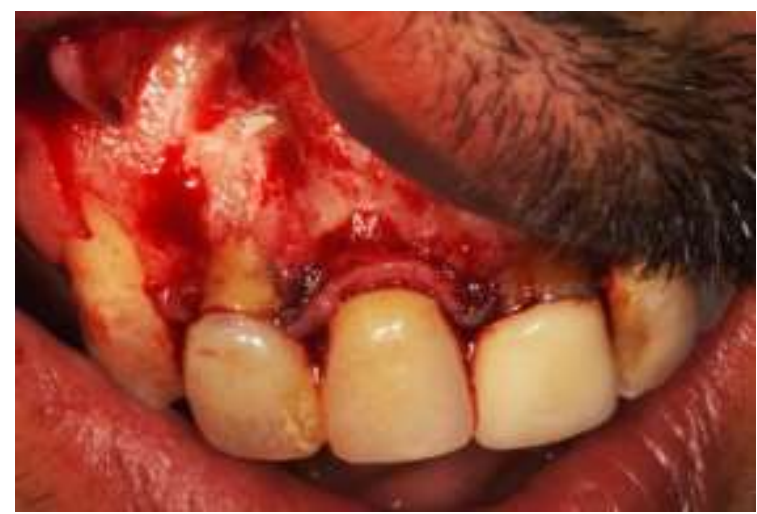

Fonte: Autores.

Para o período pós-operatório foram recomendados cuidados pós-cirúrgicos, higiene bucal, anti-inflamatórios, antibiótico e analgésico.

O material foi encaminhado para exame anatomopatológico (Figura 17), confirmando o diagnóstico de cisto periapical. Após 15 dias o paciente retornou à clínica para remoção de sutura e avaliação da área operada. Foi solicitada uma radiografia periapical da área e pôde-se observar na região radiolúcida, uma boa acomodação do material obturador no leito e um ótimo aspecto de cicatrização dos tecidos moles (Figura 18). 
Figura 13 - Membranas e plugs de A$\mathrm{PRF}+$.

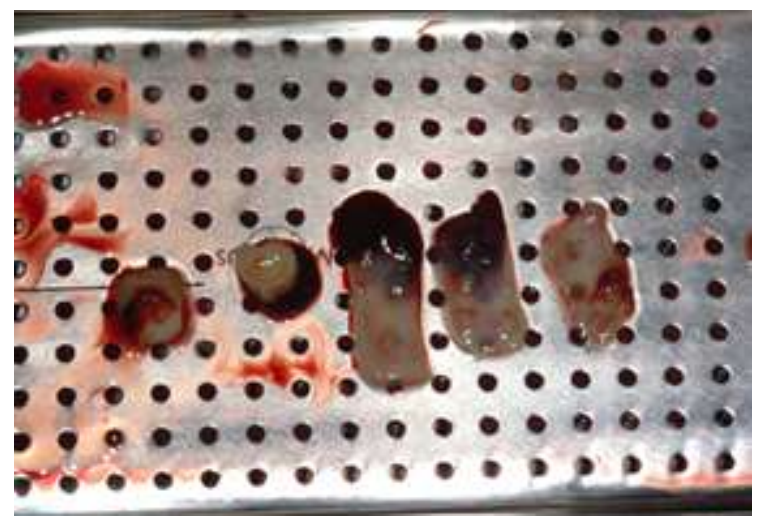

Figura 15 - Membranas posicionadas externas a lesão.

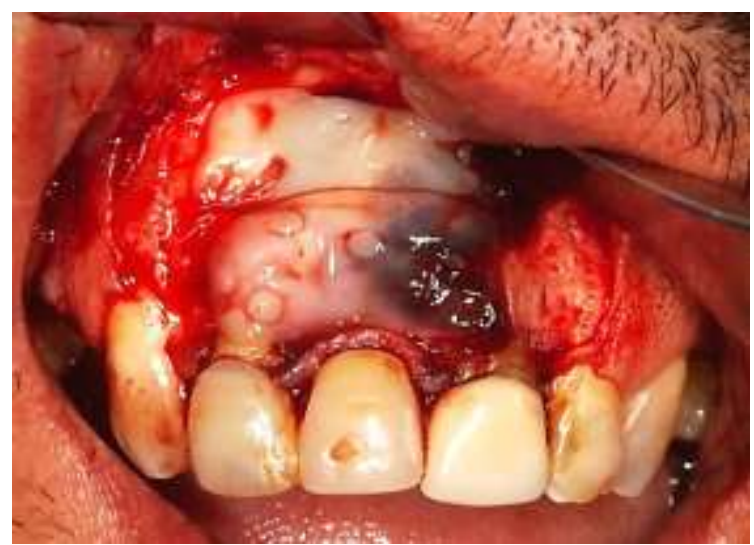

Figura 14 - Cavidade preenchida por três membranas/ plugs.

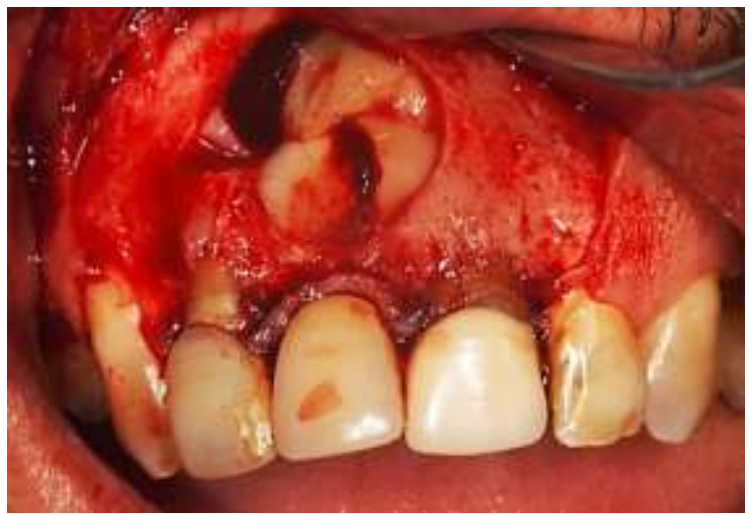

Figura 16 - Sutura por meio de pontos simples.

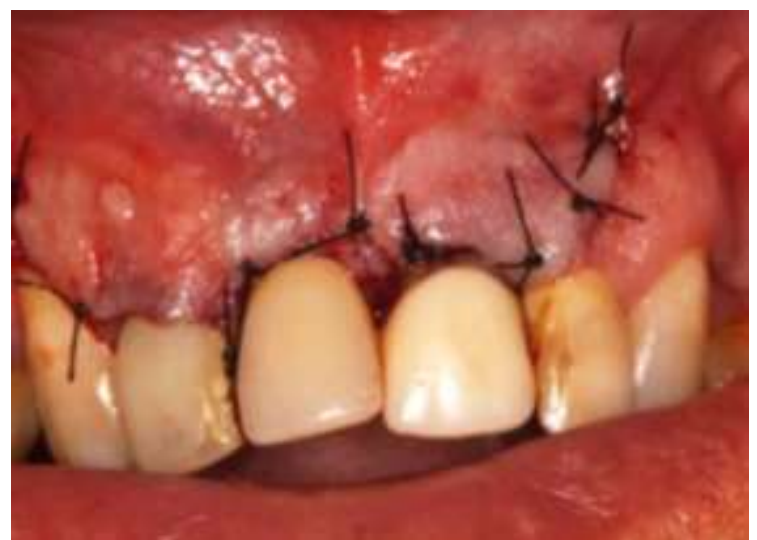

Figura 17 - Cisto.

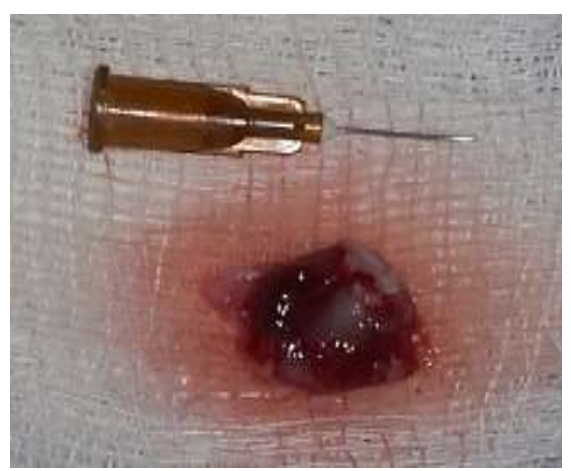

Figura 18 - Radiografia Periapical final.

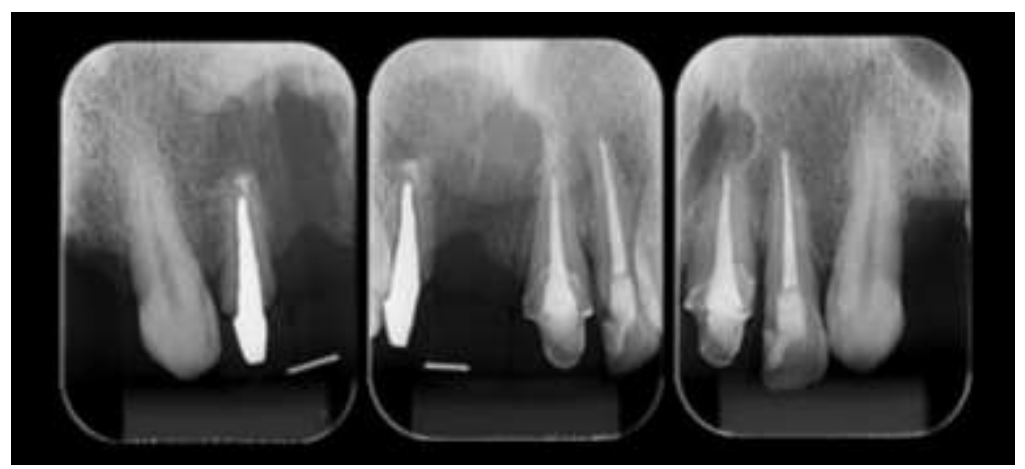

Fonte: Autores.

\section{Discussão}

Cistos são cavidades patológicas revestidas por epitélio, que podem conter fluidos ou restos celulares e tem origem odontogênica (Dantas, et al., 2014; Peixoto \& Peixoto, 2012). O conteúdo cístico é váriado, onde comumente encontram-se cristais de colesterol (Guaraldi \& Heringer, 2019; Santos, Ramos, Meira, Figueiredo, \& Santos, 2006). Estão associados a dentes desvitalizados e encontram-se localizados em região perirradicular dos mesmos (Mendonça, Conceição, Martins, \& 
Lima, 2017). Por vezes, o cisto radicular aparece como um achado radiográfico, assintomático ou como queixa principal, o paciente poderá relatar uma dor aguda ocasionada por um abcesso (Costa, et al., 2018; Dantas, et al., 2014; Neville, Damm, Allen, \& Chi, 2016; Pavelski, Portinho, CasaGrande-Neto, Griza, \& Ribeiro, 2016). Resíduos de Malassez comumente dão origem ao epitélio do cisto, podendo ser também revestimento sinusal, epitélio crevicular ou revestimento epitelial dos tratos fistulosos (Neville, et al., 2016). No caso clínico relatado, o paciente não se queixava de dor ou qualquer incômodo envolvendo a região acometida. A lesão foi descoberta durante exame clínico intraoral e levantou suspeita de cisto perante a circunstância de envolvimento com dentes não vitais e características do aumento volumétrico identificado, vindo a hipótese a ser confirmada após remoção da lesão e resultado do exame anatomopatológico.

Dandotikar et al. (2013) e Silva et al. (2018) mencionam que a escolha do tratamento dos cistos periapicais varia de acordo com a extensão da lesão. Preconiza-se inicialmente, o tratamento endodôntico para lesões com pequenas dimensões a fim de se remover o estímulo inflamatório, cessando a proliferação epitelial e favorecendo reparo tecidual. Torres-Lagares, Segura- Egea, Rodríguez-Caballero, Llamas-Carreras e Gutiérrez-Pérez (2011) e Silva et al. (2018) afirmam que em cistos periapicais de grandes proporções a terapêutica mais apropriada é o tratamento endodôntico dos dentes envolvidos, com ou sem apicectomia e tratamentos cirúrgicos como marsupialização e enucleação cística. O elemento 12, apresentou um cisto de grande proporção, dispunha de um pino intrarradicular de grande extensão, com risco de fratura do dente caso o pino fosse removido e o retratamento endodôntico fosse realizado. $\mathrm{O}$ tratamento de escolha foi a apicectomia seguida de retrobturação para preservação do remanescente dental.

Quando o tratamento endodôntico convencional (terapêutica não cirúrgica) não é capaz de eliminar a fonte de infecção de dentes com patologia apical, a endodontia cirúrgica é um tratamento opcional (Pinto, 2012; Tsesis, Rosen, Schwartz-Arad, \& Fuss, 2006). Dentre as cirurgias da região periapical, destacam-se a curetagem apical, a apicectomia e a retrobturação (Ferreira, 2017; Silva, et al., 2016).

Como material obturador, quase todos os materiais dentários restauradores e cimentos já foram propostos (Chong, Pitt Ford, Hudson, 2003; Pinto, 2012). Como requisitos, estes devem ser capazes de prover um selamento hermético adequado, serem biocompatíveis, além de serem capazes de regenerar o ligamento periodontal (Ferreira, 2017; Silva, et al., 2016). O material obturador utilizado foi o Agregado de Trióxido Mineral (MTA) que tem demonstrado em estudos ser um material com diversas propriedades não disponíveis nos demais materiais empregados atualmente em endodontia.

Desenvolvido por Choukroun na França, visando a sua aplicação em cirurgia oral e maxilofacial, a fibrina rica em plaquetas (PRF) é um concentrado plaquetário de apresto extemporâneo designado ao uso autólogo. A sua proposta é ocasionar uma melhor e mais rápida cicatrização e reparo das lesões cirúrgicas (Takamori, Teixeira, Menezes, Carias, \& Borojevic, 2018). Os concentrados sanguíneos são uma nova modalidade de estratégia para reconstrução óssea (Ferreira, 2017). Esta técnica consiste em sangue centrifugado, sem qualquer adição de anticoagulante, trombina bovina ou qualquer outro agente gelificante. Assim, é possível evitar todas as restrições relacionadas ao reimplante de produtos derivados do sangue, de acordo com a lei francesa. O protocolo da obtenção de PRF é muito simples. Consiste em uma amostra de sangue obtida sem anticoagulante em tubos de $10 \mathrm{ml}$ que são imediatamente centrifugados a $3000 \mathrm{rpm}$ por 10 minutos. O sangue em contato com as paredes do tubo, sem anticoagulantes, implica na ativação em alguns minutos das plaquetas, liberando cascatas de coagulação (Dohan, et al., 2006).

$\mathrm{Na}$ tentativa de formar uma rede de fibrina com uma distribuição plaquetária mais uniforme e maior concentração de leucócitos, alguns autores alteraram o protocolo de centrifugação diminuindo o tempo e a velocidade; otimizando os fatores de crescimento e resposta celular. Esse conceito deu origem aos chamados PRF avançados (L-PRF e o A-PRF+). Uma distribuição uniforme de plaquetas e um maior número de granulócitos são alcançados ao se diminuir a velocidade de centrifugação, otimizando a produção de fatores de crescimento, bem como a resposta celular (Aires, et al., 2020; Fujioca- 
Kobayashi, et al., 2017; Shah, Triveni, Thomas, \& Mehta, 2017). Diante do exposto, a escolha pelo uso de A-PRF+ justifica-se pelas vantagens supracitadas, incluindo o fato de ser um protocolo de baixo custo e fácil obtenção, além de uma terapêutica que pudesse oferecer uma maior quantidade de fator de crescimento para auxiliar a regeneração da cavidade existente após remoção cística.

\section{Conclusão}

Os cistos periapicais são os cistos mais prevalentes nos maxilares e seu tratamento varia conforme conduta profissional e tamanho da lesão. Este trabalho apresenta através da inserção de concentrados sanguíneos, uma nova alternativa para auxiliar na promoção de melhor reparo tecidual de cavidades resultantes da remoção de cistos de grande extensão.

O A-PRF+ apresentou-se como uma terapêutica de relevante importância no controle do quadro inflamatório, auxiliando no processo de reparo dos tecidos moles e duros. O exame anatomopatológico confirmou o diagnóstico de cisto periapical. Sugere-se que em trabalhos futuros, autores realizem o acompanhamento longitudinal com maior tempo de proservação do paciente e área tratada, afim de obter-se dados favoráveis a estudos clínicos longitudinais.

\section{Referências}

Aires, C. C. G., Figueiredo, E. L. de, Pereira, V. B. S., Vasconcellos, R. J. de H., Sabino, M. E., \& Medeiros, M. (2020). Terapias regenerativas em implantodontia: avanços no uso da Fibrina rica em plaquetas (PRF). Revista eletrônica acervo saúde, 39, e2393. https://doi.org/10.25248/reas.e2393.2020. https://acervomais.com.br/index.php/saude/article/view/2393.

Chong, B. S., Pitt Ford, T. R., \& Hudson, M. B. (2003). A prospective clinical study of Mineral Trioxide Aggregate and IRM when used as root-end filling materials in endodontic surgery. International endodontic journal, 36(8), 520-526. https://pubmed.ncbi.nlm.nih.gov/12887380/.

Costa, D. S., de Resende, L. D. O., Assis, L. J., \& de Barros, L. C. (2018). Enucleação de cisto periapical e preenchimento com biomaterial e L-PRF: relato de caso. Trabalho de conclusão de curso apresentado a disciplina de Produção Científica, Centro Universitário de Anápolis-UniEvangélica, Anápolis, GO. http://repositorio.aee.edu.br/handle/aee/944.

Dandotikar, D., Peddi, R., Lakhani, B., Lata, K., Mathur, A., \& Chowdary, U. K. (2013). Nonsurgical management of a periapical cyst: a case report. Journal of international oral health: $\mathrm{JIOH}, 5(3), 79-84$. https://pubmed.ncbi.nlm.nih.gov/24155607/.

Dantas, R. M. X., Dultra, J. A., Borges, G. L., Dultra, F. K. A. A., \& Neri, R. F. de A. (2014). Enucleação de cisto radicular maxilar associado à apicectomia: relato de caso. Revista de Cirurgia e Traumatologia Buco-maxilo-facial, 14(3), 21-26. http://revodonto.bvsalud.org/scielo.php?script=sci_arttext\&pid=S180852102014000300004

Dohan, D. M., Choukroun, J., Diss, A., Dohan, S. L., Dohan, A. J. J., \& Mouhyi, J. et al. (2006). Fibrina rica em plaquetas (PRF): um concentrado de plaquetas de segunda geração. Parte I: conceitos e evolução tecnológica. Cirurgia Oral, Medicina Oral, Patologia Oral, Radiologia Oral e Endodontologia, 101(3), 37-44, https://doi.org/10.1016/j.tripleo.2005.07.008. https://www.sciencedirect.com/science/article/abs/pii/S107921040500586X.

Estrela, C. (2018). Metodologia Científica: Ciência, Ensino, Pesquisa. Editora Artes Médicas

Ferreira, T. A. L. (2017). Cirurgia endodôntica e retro-obturação. Dissertação apresentada como parte dos requisitos para obtenção do grau de Mestre de Medicina Dentária, Universidade Fernando Pessoa, Porto. http://hdl.handle.net/10284/6192.

Freitas, A. de, Rosa, J. E., \& Sousa, I. F. e (2000) Radiologia Odontológica. (5a ed.) Artes Médicas.

Fujioca-Kobayashi, M., Miron, R. J., Hernandez, M., Kandalam, U., Zhang, Y., \& Choukroun, J. (2017). Optimized platelet-rich fibrin with the low-speed concept: growth factor release, biocompatibility, and cellular response. Journal of periodontology, 88(1), 112-121. https://doi.org/10.1902/jop.2016.160443. https://pubmed.ncbi.nlm.nih.gov/27587367/.

Guaraldi, K. da S., \& Heringer, E. M. (2019). Tratamento do cisto periapical pela técnica de marsupialização. Cadernos de Odontologia do UNIFESO, 1(2). https://www.unifeso.edu.br/revista/index.php/cadernosodontologiaunifeso/article/view/1990.

Martins-Filho, P. R. S., Brasileiro, B. F., Piva, M. R., Silva, L. C. F., Reinheimer, D. M., \& Marzola, C. (2009) Cisto radicular na maxila relato de caso clínico cirúrgico. Rev ATO. 4(10), 881-889.

Mendonça, D. W. R., Conceicao, H. C., Martins, V. B., \& Lima, K. A. (2017). Tratamento cirúrgico de cisto radicular em maxila: relato de caso. ARCHIVES OF HEALTH INVESTIGATION, 6(8). https://doi.org/10.21270/archi.v6i8.2216. https://www.archhealthinvestigation.com.br/ArcHI/article/view/2216\# : : :text=O\%20tratamento\%20proposto\%20ent\%C3\%A3o\%20foi,para\%20o\%20tratamento\%20destas\%20les\%C3\%B5es.

Neto, M. M., Danesi, C. C., \& Unfer, D. T. (2004). Contribuição ao estudo do cisto radicular revisão da literatura. Saúde (Santa Maria), 30(1-2), 90-99. https://periodicos.ufsm.br/revistasaude/article/view/6399\#: :text=Os\%20autores\%20apresentam\%20revis\%C3\%A3o\%20da,aspectos\%20relevantes\%20associ ados\%20\%C3\%A0\%20les\%C3\%A3o. 
Research, Society and Development, v. 10, n. 6, e31010615806, 2021

(CC BY 4.0) | ISSN 2525-3409 | DOI: http://dx.doi.org/10.33448/rsd-v10i6.15806

Neville, B. W., Damm, D. D, Allen, C. M., \& $\quad$ Chi. (2016). Patologia oral $\boldsymbol{e}$ maxilofacial. (4a ed.) Elsevier. https://integrada.minhabiblioteca.com.br/\#/books/9788595151390/cfi/6/6!/4/2/48/2/2@0:0.

Pavelski, M. D., Portinho, D., CasaGrande-Neto, A., Griza, G. L., \& Ribeiro, R. G. (2016). Paraendodontic surgery: case report. RGO - Revista Gaúcha de Odontologia, 64(4), 460-466. https://doi.org/10.1590/1981-8637201600030000153161. https://www.scielo.br/scielo.php?script=sci_arttext\&pid=S1981$86372016000400460 \& \operatorname{lng}=e n \& n r m=i s o$.

Peixoto, R. F., \& Peixoto, D. F. (2012). Aspectos imunológicos e etiopatogênicos das lesões periapicais inflamatórias crônicas. Journal of Health Sciences, 14(3). https://doi.org/10.17921/2447-8938.2012v14n3p\%25p. https://revista.pgsskroton.com/index.php/JHealthSci/article/view/938.

Peterson, L. J. (2000). Cirurgia oral e maxilofacial contemporânea. (3ª . Ed.) Rio de Janeiro: Guanabara. https://pesquisa.bvsalud.org/portal/resource/pt/lil625759 .

Pinto, M. .J. V. C. R. (2012). Cirurgia Endodôntica e Materiais Retroturadores. Tese apresentada como parte dos requisitos para obtenção do grau de Mestre em Medicina Dentária, Universidade Fernando Pessoa, Porto.

Santos, L. C. S., Ramos, E. A. G., Meira, T. M., Figueiredo, C. R. L. V. de, \& Santos, J. N. dos (2006). Etiopatogenia do cisto radicular. Parte I. R. Ci. méd. biol., Salvador, 5(1), 69-74. https://www.arca.fiocruz.br/handle/icict/10232.

Shah, R., Triveni, M. G., Thomas, R., \& Mehta, D. S. (2017). Uma atualização sobre os protocolos e ações biológicas da fibrina rica em plaquetas em odontologia. The European journal of prostodontics and restaurative dentistry, 25(2), 64-72. https://europepmc.org/article/med/28590091.

Silva, R. N. F., Vilela, A. C. S., Ferreira, A. B., Silva, B. G., Vêncio, E. F., \& Decúrcio, D. de A. et al. (2018). Tratamento de cisto radicular de grande extensão: relato de caso clínico. Revista Odontológica do Brasil Central, 27(80). https://www.robrac.org.br/seer/index.php/ROBRAC/article/view/1172.

Silva, S. R. da, Silva Neto, J. D. da, Schnaider, T. B., Veiga, D. F., Novo, N. F., Mesquita Filho, M., \& Ferreira, L. M. (2016). The use of a biocompatible cement in endodontic surgery. A randomized clinical trial 1. Acta Cirúrgica Brasileira, 31(6), 422-427. https://doi.org/10.1590/S0102-865020160060000010. https://www.scielo.br/scielo.php?script=sci_arttext\&pid=S0102-86502016000600422.

Takamori, E. R., Teixeira, M. V. T., Menezes, K., Carias, R. B. V., \& Borojevic, R. (2018). Fibrina rica em plaquetas: preparo, definição da qualidade, uso clínico. Vigilância Sanitária em Debate: Sociedade, Ciência \& Tecnologia (Health Surveillance under Debate: Society, Science \& Technology) -Visa em Debate, 6(1), 118-124. https://doi.org/10.22239/2317-269x.01044. https://visaemdebate.incqs.fiocruz.br/index.php/visaemdebate/article/view/1044.

Tommasi, A. F. (2002). Diagnóstico em patologia bucal. (3a ed.) Pancast. https://pesquisa.bvsalud.org/portal/resource/pt/biblio-862780.

Torres-Lagares, D., Segura-Egea, J. J., Rodríguez-Caballero, A., Llamas-Carreras, K. M., \& Gutiérrez-Pérez, J. L. (2011). Treatment of a large maxillary cyst with marsupialization, decompression, surgical endodontic therapy, and enucleation. J Can Dent Assoc, 77:b87. https://pubmed.ncbi.nlm.nih.gov/21736863/.

Tsesis, I., Rosen, E., Schwartz-Arad, D., \& Fuss, Z. (2006). Retrospective evaluation of surgical endodontic treatment: traditional versus modern technigue. Journal of Endodontics, 32(5), 412-416. 10.1016 / j.joen.2005.10.051. https://pubmed.ncbi.nlm.nih.gov/16631838/.

Vasconcelos, R. G., Queiroz, L. M. G., Alves Júnior, L. C., Germano, A. R., \& Vasconcelos, M. G. (2012). Aboradagem terapêutica em cisto radicular de grandes proporções: relato de caso. Revista Brasileira de Ciências da Saúde, 16(3), 467-474. https://repositorio.ufrn.br/jspui/handle/123456789/24306. 